\section{Equivalência conceitual, de itens e semântica do Physical Activity Checklist Interview (PACI)}

\author{
Conceptual, item, and semantic equivalence of a \\ Brazilian version of the Physical Activity Checklist \\ Interview (PACl)
}

\author{
1 Faculdade de Saúde \\ Publica, Universidade de São \\ Paulo, São Paulo, Brasil. \\ Correspondência \\ F. Adami \\ Faculdade de Saúde Pública, \\ Universidade de São Paulo. \\ Rua Dr. Arnaldo 715, \\ São Paulo, SP \\ 01255-000, Brasil. \\ adamifernando@uol.com.br
}

\begin{abstract}
There is a lack of Brazilian questionnaires to assess physical activity in children. The Physical Activity Checklist Interview (PACI) was originally developed for North American children and allows assessing physical activity during the previous day. The objectives of this study were: $i$ ) to describe procedures for choosing the PACI for crosscultural adaptation and ii) to assess conceptual, item, and semantic equivalence of the Brazilian version to be used with 7-to-10-year-old children. PACI was identified from a systematic review of 18 questionnaires. The process of choosing the instrument involved discussions with researchers. The PACI allows assessing the construct and its dimensions. Some kinds of physical activity that are uncommon in the Brazilian population had to be eliminated. The following steps were taken to evaluate semantic equivalence: translation, retranslation, connotative and referential meaning assessment, and a pretest with 24 children aged 7 to 10 years. We present the PACI in its Brazilian adapted version, called Lista de Atividades Físicas (LAF).
\end{abstract}

Motor Activity; Questionnaires; Child

\author{
Fernanda Cruciani 1 \\ Fernando Adami 1 \\ Nathalia Antiqueira Assunção 1 \\ Denise Pimentel Bergamaschi 1
}

\section{Introdução}

Atividade física é definida como movimento corporal produzido por contrações do músculo esquelético que resulta em um incremento do gasto energético além dos níveis de repouso ${ }^{1}$, sendo reconhecida como indispensável ao controle e prevenção de algumas doenças crônicas em todas as faixas etárias 2 .

A obesidade infantil é um problema mundial de saúde pública que afeta de modo importante a população brasileira, constituindo um campo de pesquisa no qual a aferição da atividade física é imprescindível. No contexto da pesquisa epidemiológica, torna-se essencial a existência de instrumentos de aferição deste construto que apresentem bons indicadores psicométricos.

Questionários são instrumentos de coleta de dados amplamente utilizados para aferição de atividade física, pois são de baixo custo, fácil aplicação, não interferem na privacidade dos indivíduos nem na execução das atividades diárias, reúnem informações da atividade num determinado período (dias, semanas, meses ou anos) e permitem avaliar um grande número de pessoas em um curto espaço de tempo ${ }^{3}$.

Existe lacuna de estudos brasileiros que propõem instrumentos de aferição de atividade física em grupos populacionais abaixo dos 10 anos. Barros et al. ${ }^{4}$ propuseram um questionário validado com base na comparação de informações referidas por escolares de 7 a 10 anos com 
as de seus pais. Esse instrumento foi utilizado em grupo populacional de mesma faixa etária do Município de São Paulo; entretanto, 98\% dos escolares apresentaram escores abaixo do nível mediano da escala apresentada, indicando que o instrumento proposto pode não ser adequado para este grupo populacional 5 .

$\mathrm{Na}$ ausência de instrumentos nacionais, é possível utilizar questionários desenvolvidos em outras culturas desde que sejam adaptados à cultura em que será utilizado. Nesse caso, pode-se utilizar procedimentos já consolidados de adaptação transcultural que consistem em uma série de passos metodológicos criteriosos que orientam a criação da versão adaptada. Segundo Reichenheim \& Moraes 6 , os passos que devem ser atendidos numa adaptação transcultural são: equivalência conceitual, de itens, semântica, operacional e de mensuração.

O Physical Activity Checklist Interview (PACI) foi originalmente proposto e validado por Sallis et al. 7 para uso em crianças americanas e permite aferir atividade física do dia anterior, sendo utilizado somente em dias escolares. O estudo original foi desenvolvido com estudantes da $5 \underline{a}$ série (55 meninos e 70 meninas) e idade média de 10,9 anos (DP $=0,53)$.

O PACI é dividido em três partes: seção A, destinada ao preenchimento de dados gerais da entrevista, tais como nome da criança, série, horário de início e fim da entrevista; seção $\mathrm{B}$, que consiste de uma lista de 21 atividades físicas de intensidades moderadas a vigorosas e espaço para o preenchimento de outras atividades físicas, bem como uma seção para relato de atividades sedentárias (tempo assistindo à televisão/vídeo e jogando jogos de vídeo game ou usando computador); e seção C, destinada à avaliação da entrevista, devendo ser preenchida pelo entrevistador após o término da mesma.

Na seção B, são registrados os minutos gastos com cada atividade física durante três períodos do dia anterior: antes, durante e depois do período escolar, com o relato do tempo de engajamento em atividades realizadas por cinco minutos ou mais. Nesta seção se investiga também a percepção de esforço por meio da pergunta: “Quando você andou de bicicleta por 5 minutos ou mais ontem antes da escola, você sentiu dificuldade para respirar ou sensação de cansaço nunca, às vezes ou na maior parte do tempo?".

O PACI permite quantificar: (i) minutos em atividades sedentárias; (ii) número de atividades relatadas; (iii) minutos de atividades físicas moderadas a vigorosas; (iv) somatório dos escores de MET (equivalente metabólico) das atividades relatadas (minutos $\mathrm{x}$ valor de MET de cada atividade física); (v) somatório dos escores de MET ponderados (minutos x valor de MET x percepção subjetiva do esforço). Os valores de MET das atividades físicas da Lista de Atividades Físicas (LAF) são obtidos do Compêndio de Atividades Físicas construído por Ainsworth et al. 8.

O PACI, em sua versão original, apresenta estimativas de confiabilidade e validade concorrente dependendo do item (i a v) avaliado. Em relação à confiabilidade, os valores do coeficiente de correlação intraclasse variam entre 0,64 a 0,79. Para a validade concorrente, adotando como medida critério valores do acelerômetro, os valores do coeficiente de correlação de Pearson variam de 0,10 a 0,387 .

Os objetivos do estudo foram: (i) descrever os procedimentos para a escolha do PACI, questionário para aferição de atividade física validado em outra cultura, a ser submetido à adaptação transcultural; (ii) apresentar os resultados da apreciação das equivalências conceitual, de itens e semântica da versão brasileira em português do instrumento PACI para uso em crianças de 7 a 10 anos.

\section{Métodos}

Estudo de adaptação transcultural do PACI para produção da versão em português, seguindo o modelo universalista e passos metodológicos propostos inicialmente por Herdman et al. 9,10 com adaptação e sistemática operacional propostas por Reichenheim \& Moraes 6 . O presente estudo cumpre as etapas de avaliação das equivalências conceitual, de item e semântica, com pré-teste do instrumento adaptado para o português (Figura 1).

Para a identificação do questionário a ser adaptado, procedeu-se a um levantamento sistemático da literatura com adoção de estratégias de busca segundo bases de dados (PubMed, LILACS e Sport Discus). As estratégias foram elaboradas com base em três conjuntos de palavras-chave, estabelecidos nas referências de artigos considerados importantes para o assunto e incluíam palavras referentes: (i) ao assunto de interesse (atividade física); (ii) ao instrumento, no caso questionário de atividade física; e (iii) à população de interesse (crianças). O período de cobertura adotado para busca foi de 1993 a 2006. O resultado de cada busca foi documentado de tal forma que fosse possível a repetição do processo 11.

Constituíram critérios de elegibilidade: artigos que utilizavam questionários de aferição de atividade física, ser relativo a crianças de 7 a 10 anos ou que abrangesse pelo menos parte desta faixa etária e que apresentassem reprodutibili- 


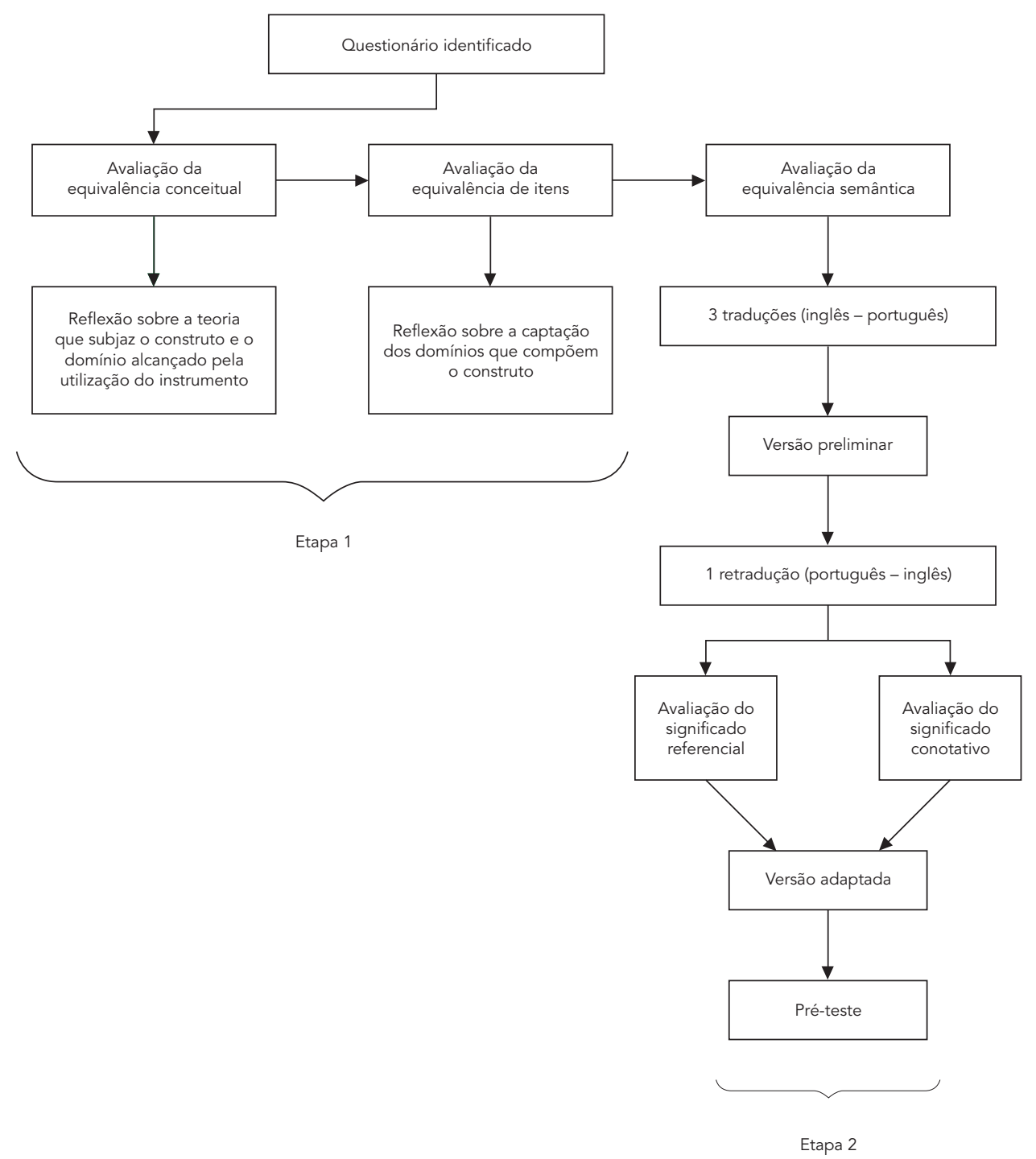

dade ou validade testadas. Todos os resumos elegíveis foram lidos, de forma independente, por dois avaliadores para identificação dos artigos que seriam lidos na íntegra. Dois avaliadores, de modo independente, leram os textos na integra e foram extraídas as principais informações (faixa etária, objetivo do questionário, forma de administração, composição, formas de respostas e tipo de variável resultante da aplicação do instrumento). Fundamentados nessas informa- ções, três pesquisadores envolvidos no estudo classificaram os questionários, de modo independente e em ordem crescente, orientados pelos critérios citados anteriormente. Por meio de discussão e consenso, foram identificados três questionários com potencialidade para adaptação transcultural.

Com o objetivo de ampliar a discussão e recolher subsídios para a escolha final, três profissionais da área da Educação Física foram convidados 
a participar da etapa de seleção do questionário a ser adaptado. Foram enviadas informações detalhadas sobre todos os questionários identificados e os pré-selecionados, realizando-se reuniões separadamente com cada profissional. $\mathrm{O}$ foco de tais discussões foi voltado à aferição de atividade física, envolvendo suas dimensões, pois se buscava um instrumento que cobrisse o maior espectro possível de mensurabilidade do construto. A forma de aplicação do questionário (por entrevista ou autopreenchido), e o período de tempo de cobertura da atividade física foram muito discutidos. Avaliou-se também a composição do questionário, o número de questões, a forma de resposta que era solicitada, bem como a forma de análise dos resultados. A aplicabilidade do questionário também foi alvo de análise, identificando-se como necessário às características de fácil aplicação, baixo custo e não-interferência na rotina diária dos participantes.

Etapa 1: avaliação de equivalências conceitual e de itens

Na avaliação da equivalência conceitual, procurou-se explorar o construto de interesse (atividade física) na sua definição original e na cultura brasileira em que o instrumento seria utilizado, por meio de discussão com três profissionais da área de Educação Física e de estudo da literatura. Foi revisado o modelo conceitual que dá sustentação teórica ao construto e, com base nele, analisou-se o campo de cobertura do instrumento a ser adaptado, especialmente no que se refere às características de mensuração. Nessa etapa os escolares não foram envolvidos.

A equivalência de itens constou da apreciação da pertinência dos itens pela avaliação das questões que identificam os domínios do instrumento original na cultura alvo. Para essa etapa, foi utilizada revisão bibliográfica e discussões com três especialistas da área, sem envolvimento dos escolares.

\section{Etapa 2: avaliação de equivalência semântica}

Na avaliação da equivalência semântica, procurou-se averiguar a capacidade de transferência de sentido dos conceitos contidos no instrumento original para a versão adaptada, com o objetivo de assegurar efeitos semelhantes nos respondentes das duas culturas.

Nessa etapa, realizou-se de forma independente a tradução do instrumento original para o português por três tradutores. Dois eram profissionais com experiência na área de saúde e foram informados sobre os objetivos do estudo; o terceiro era um tradutor juramentado, que des- conhecia os objetivos do estudo. Com base nas três traduções, compôs-se a primeira versão do questionário adaptado com base num quadro que continha frases do documento original e de cada tradutor. Participaram dessa etapa três pesquisadores, sendo o autor do questionário original contatado para esclarecimentos. Essa versão foi traduzida para o inglês (back translation) com a participação de um novo tradutor que apresentava o inglês como língua mãe. Em nenhum momento o profissional teve contato com a versão original do questionário, nem foi informado sobre a autoria do mesmo.

Foi construído um documento que continha frases do instrumento original e da versão retraduzida para o inglês, dispostas em colunas sem identificação da versão a que pertenciam. O documento serviu como base para avaliação da equivalência semântica feita por um novo tradutor que tinha como idioma pátrio o inglês. Foram seguidos, nesta etapa, os modelos de avaliação dos significados lingüísticos referencial (literal) e conotativo (geral) adaptados por Reichenheim \& Moraes 6 e Moraes et al. 12.

O primeiro diz respeito à correspondência literal entre o original e sua tradução. Utilizou-se a Escala Visual Analógica que revela o grau de correspondência literal entre os significados por meio de escores que variam de $0 \%$ a $100 \%$, aferidos em uma régua de $10 \mathrm{~cm}$ de comprimento. Se houvesse concordância sobre o significado literal, o avaliador marcaria um $\mathrm{X}$ próximo ao $0 \%$ que indicava sem modificação (SM) e, na presença de modificação importante no significado, $\mathrm{o}$ avaliador assinalaria um $\mathrm{X}$ no extremo direito da linha, próximo a 100\%, indicando versão com modificação (CM).

O significado conotativo (geral) de cada item foi avaliado pela resposta emocional evocada por uma palavra, comparando-se os itens do documento original com os da tradução. A avaliação foi feita por meio de um questionário que averiguava a correspondência conotativa em quatro níveis: significado inalterado, pouco alterado, muito alterado (MA) ou completamente alterado (CA) 6,12.

Calcado nessas avaliações, para as frases identificadas como contendo alterações importantes (Escala Visual Analógica com escore maior ou igual a $30 \%$ ou MA e CA presentes), procedeu-se à reflexão sobre o tipo de alteração e implicações frente aos conceitos envolvidos na definição de atividade física. Nessa etapa foi construída a primeira versão do questionário em português.

Realizou-se pré-teste após o treinamento dos avaliadores, que utilizaram frases do questionário em forma de vinhetas e orientações especí- 
ficas para o preenchimento, buscando homogeneidade na realização das entrevistas. Buscou-se averiguar aspectos da utilização do instrumento adaptado na população alvo, sendo entrevistadas 24 crianças de 7 a 10 anos durante o período escolar, sorteadas de modo aleatório simples entre todos os escolares de 1ạ a 4a série do Ensino Fundamental da Escola de Aplicação da Universidade de São Paulo - USP ( $=240)$. Após o préteste, obteve-se a versão final do instrumento adaptado (Figura 2).

O estudo foi aprovado pelo Comitê de Ética em Pesquisa para Seres Humanos da Faculdade de Saúde Pública/USP e seu desenvolvimento ocorreu a partir da assinatura de termos de consentimento livre e esclarecido pelos responsáveis das crianças. O pesquisador James Sallis autorizou a realização da adaptação transcultural do instrumento PACI.

\section{Resultados}

No levantamento bibliográfico, foram localizados inicialmente 149 resumos, dos quais dezoito atenderam aos critérios de elegibilidade e foram lidos na íntegra. Quatorze não foram selecionados em razão dos seguintes motivos: grande amplitude de faixa etária $(n=5)$, envolvimento somente de atividades realizadas fora do período escolar $(n=4)$, solicitação de que o indivíduo classificasse a intensidade da atividade realizada $(n=2)$, necessidade de pais e professores registrarem as informações $(n=2)$, avaliação da atividade física realizada no mês anterior $(\mathrm{n}=1)$, desenvolvido para grupos populacionais específicos $(\mathrm{n}=3)$, tradução de outro idioma $(n=1)$, uso da escala de Likert $(n=2)$, e administrado com uso de computador $(\mathrm{n}=1)$. Alguns desses aspectos podiam estar presentes simultaneamente nos questionários 11 .

Três instrumentos foram identificados como possíveis para serem submetidos à procedimento de adaptação transcultural: PACI 7; Physical Activity Questionnaire for Older Children (PAQ-C) 13,14 e Godin-Shephard Questionnaire 15, decidindo-se pela adaptação do primeiro instrumento, o PACI 7.

O PACI foi selecionado por apresentar as seguintes características: (i) inclui uma lista de atividades físicas que auxilia na lembrança das atividades realizadas; (ii) é estruturado segundo períodos do dia (antes, durante e após a escola) contribuindo para a diminuição de erros de memória; (iii) apresenta orientações e reforço de conceitos sobre noção de tempo, atividade física e períodos do dia; (iv) apresenta boas propriedades psicométricas; (v) permite a aferição de atividade física de modo prático; (vi) tem como respondente a criança.

\section{Etapa 1: avaliação de equivalências conceitual e de itens}

A comparação do construto "atividade física” no país de origem e na população alvo, tendo como base a definição proposta por Caspersen et al. 1, revelou que (i) tanto no país de origem como na população alvo, o questionário permite aferir atividade física realizada no dia anterior. O instrumento apresenta uma lista de atividades físicas classificadas nas intensidades de moderada à vigorosa de acordo com o gasto energético apresentado no compêndio internacional de atividade física de Ainsworth et al. 8; (ii) as dimensões do construto: atividades de lazer, domésticas, transporte e ocupacionais são representadas de modo semelhante em ambas as culturas; (iii) a atividade física é aferida em ambas as culturas pelo cálculo do somatório do custo metabólico das atividades: tempo em atividade (minutos) $\mathrm{x}$ intensidade da atividade segundo compêndio de Ainsworth et al. 8; (iv) a apresentação das atividades físicas segundo período do dia é aplicável também na população alvo, uma vez que na faixa etária de 7 a 10 anos a organização do dia está centrada no período escolar; (v), identificação da presença das dimensões do construto pela lista de atividades do questionário original: atividades de lazer, domésticas, transporte e ocupacional. As atividades de lazer correspondem aos itens de 1 a 15 (bicicleta, jogos com bola, brincadeiras) e aos itens 18 a 21 (exercícios, caminhada, corrida). As atividades domésticas correspondem aos itens 16 e 17 (tarefas ao ar livre, tarefas dentro de casa), as atividades de transporte estão cobertas nos itens 1, 19, 20 e 21 (andar de bicicleta, caminhar, correr) e finalmente, as atividades ocupacionais seriam todas aquelas realizadas no período escolar, incluindo as aulas de Educação Física; (vi) o questionário apresenta um quadro contendo atividades sedentárias comuns na população de origem e na alvo: tempo despendido diante da televisão, computador e vídeo-game, avaliados nos períodos antes e depois da escola.

\section{Etapa 2: avaliação da equivalência semântica}

Para o processo de construção do questionário adaptado foram suprimidos, substituídos ou acrescentados termos gerais ou relativos ao tipo de atividade física conforme visto na Tabela 1 . A análise da retradução resultou, para significado referencial, 17,6\% de itens com modificações identificadas como importantes (escore > 30\%) e, para o significado conotativo, $70 \%$ dos itens 


\section{LISTA DE ATIVIDADES FÍSICAS (LAF) * ORIENTAÇÕES GERAIS}

O LAF é dividido em Instruções para entrevista e Questionário com 3 seções - A, B e C. O conteúdo das Instruções orienta as falas dos entrevistadores, com exceção do texto entre colchetes, que contém informações relativas à condução da entrevista. Na seção $\mathrm{A}$ do questionário, são anotados dados da criança; na $\mathrm{B}$, dados das atividades físicas e de atividades sedentárias do dia anterior; e a $\mathrm{C}$ se refere à avaliação da entrevista. Na sessão B, registre o tempo, em minutos, para cada atividade física relatada pela criança nas colunas B, D e G. Use uma folha em branco para auxiliar na soma de minutos de cada atividade realizada. Coloque um traço se a atividade física não foi realizada. Ao final de cada entrevista, preencha a Seção C, o horário de término e o número de identificação da criança (ID) nos campos específicos localizados no topo de cada folha. Não anotar nada fora dos campos específicos do questionário LAF. Deve-se iniciar a entrevista identificando-se.

\section{INTRODUÇÃO}

\section{INSTRUÇÕES PARA ENTREVISTA}

Vamos conversar sobre a atividade fí sica que você fez ONTEM. Que dia da semana foi ontem? Atividade física é o movimento do corpo em que você mexe seus braços e pernas. Em algumas atividades físicas, você se movimenta de um lugar para outro, como correr ou caminhar. Que outras atividades físicas são assim? Algumas atividades físicas podem ser feitas sem sair do lugar, como polichinelos e abdominais. Você pode me dizer outras atividades físicas que podem ser feitas sem sair do lugar?

\section{TEMPO}

Vamos perguntar quanto tempo de atividade física você fez ontem. O relógio vai ajudá-lo a nos dizer [neste momento, o entrevistador mostra à criança um círculo em forma de relógio com 60 minutos e figuras geométricas que representam 30, 15 e 5 minutos] **. Quantos minutos têm este relógio todo? O que dura 60 minutos? Algumas coisas duram 30 minutos. Qual destes pedaços representa 30 minutos? [A criança segura o relógio, e coloca as peças nos lugares corretos]. O que você conhece que dura 30 minutos? Qual pedaço representa 15 minutos? O que você conhece que dura 15 minutos? Quantos minutos duram este último pedaço? [mostrar o pedaço correspondente a 5 minutos]. O que você conhece que dura 5 minutos? Queremos que você nos conte as atividades físicas que você fez ontem e que duraram 5 minutos ou mais. Vamos ver se conseguimos ter uma idéia do que dura 5 minutos ou mais.

Comercial de TV? [Criança responde mais ou menos que 5 minutos?]

Caminhar do carro até a escola? [mais ou menos que 5 minutos?]

Escovar os dentes? [mais ou menos que 5 minutos?]

Recreio? [mais ou menos que 5 minutos?]

Almoçar? [mais ou menos que 5 minutos?]

Você pode fazer uma atividade física por 5, 10, 20 ou mais de 60 minutos.

\section{TEMPO REALMENTE EM ATIVIDADE}

Às vezes, durante jogos ou atividades físicas, você pode parar e fazer outra coisa, como descansar ou esperar na fila. Nós estamos interessados somente no tempo em que você realmente fez atividade física. Por exemplo, se você saiu para andar de bicicleta por 20 minutos, mas parou uma vez para entrar na casa de um amigo por 5 minutos, você de fato andou ativamente de bicicleta por 15 minutos.

\section{INTRODUÇÃO DA LISTA DE ATIVIDADES}

Vamos dividir o dia em 3 partes: antes da escola, durante a escola e depois da escola. Para cada parte, vamos perguntar que atividade física você fez ontem, durante 5 minutos ou mais, usando uma lista [mostrar Seção B do LAF]. Pode ser que você não tenha feito alguma ou nenhuma destas atividades físicas, não tem problema. Gostaríamos também de saber sobre as atividades físicas que você fez ontem e que não estejam na lista.

* Adaptado de Physical Activity Checklist Interview: Sallis JF, Strikmiller PK, Harsha DW, et al. Validation of interviewer-and self-administered physical activity checklists for fifth grade students. Med Sci Sports Exerc 1996; 28(7):840-51.

** Ver esquema do relógio em anexo. 


\section{ENTREVISTA}

\section{A. Antes da Escola}

Pense sobre ontem no período antes da escola. Este período vai desde que você acordou até o sinal da escola tocar para a aula começar e inclui atividades realizadas antes da aula começar. O que você fez de modo geral ontem antes de ir para a escola? Algo especial antes da escola? Pense nas atividades físicas que você fez por 5 minutos ou mais ontem, antes da escola. [Use a lista de atividades do inicio ao fim perguntando somente sobre ontem ANTES DA ESCOLA. Dê uma breve explicação antes de perguntar sobre Caminhada, Corrida e Combinação de Caminhada e Corrida. Para cada atividade referida, pergunte se eles sentiram sinais corporais de "dificuldade para respirar" ou "sensação de cansaço" nunca, às vezes ou na maior parte do tempo, anotando as iniciais $\mathrm{N}$ para nunca, $\mathrm{AV}$ para às vezes e MPT para maior parte do tempo nas colunas $\mathrm{C}, \mathrm{E} \mathrm{e} \mathrm{H}]$.

1 Você ontem antes da escola por 5 minutos ou mais?

2 Quantos minutos você realmente gastou ?

3 Durante os_minutos em que você esteve respirar" ou "sensação de cansaço" nunca, às vezes ou na maior parte do tempo? outras vezes antes da escola? [Caso a resposta seja afirmativa, repita a questão 2 perguntando Quantos minutos você realmente gastou DESSA VEZ, e anote na folha auxiliar. Some os minutos e anote no questionário o tempo total]

[Somente para a atividade Exercícios: flexões de braço, abdominais, polichinelos] Você incluiu em alguma outra atividade esse tempo que ficou realizando esses exercícios? Caso afirmativo, pergunte "Qual atividade você fez?" e repita as perguntas de 2 a 4 .

\section{* Antes de perguntar sobre o tempo de CAMINHADA e CORRIDA, explique:}

Nós caminhamos e corremos muitas vezes durante o dia. Grande parte dessas atividades é curta, não duram nem 5 minutos. Vamos falar sobre o que você fez por 5 minutos ou mais, como fazer uma caminhada, andar até algum lugar ou levar seu cachorro para passear.

Antes de ir para escola, você caminhou por mais de 5 minutos seguidos? Quando foi a primeira vez que você caminhou por mais de 5 minutos seguidos? Segunda vez? Alguma vez mais? Você incluiu em alguma outra atividade esse tempo que ficou caminhando? [anote o número de vezes, some-as e faça um círculo no total].

[Repetir a seqüência de perguntas para a atividade Corrida].

* Antes de perguntar sobre COMBINAÇÃO DE CAMINHADA E CORRIDA, explique:

Às vezes, é possível correr por uns minutos e depois caminhar por uns minutos e em seguida correr um pouco mais.

Ontem antes da escola, você fez alguma combinação de caminhada e corrida por mais de 5 minutos? Você incluiu em alguma outra atividade esse tempo que ficou caminhando/correndo?

* Na categoria OUTROS, pergunte sobre cursos, aulas extras e treinos.

Além do que já foi dito, você fez algum outro curso, aulas extras ou treinos ontem antes da escola?

\section{B. Durante a Escola}

[Use a lista de atividades e pergunte sobre as realizadas DURANTE A ESCOLA ontem. Procure averiguar a intensidade. Ressaltar que este período vai desde o sinal da escola tocar para a aula começar até o sinal da escola tocar para a aula acabar. Durante a escola, não é necessário perguntar sobre a atividade de número 17].

1 Você__ontem durante a escola por 5 minutos ou mais?

[Para as atividades Exercícios, Caminhada, Corrida e Combinação de caminhada e corrida, perguntar se a criança já incluiu em outra atividade o tempo que ela gastou nessas atividades]

2 Quantos minutos você realmente gastou

3 Durante os minutos em que você esteve ? respirar" ou "sensação de cansaço" nunca, às vezes ou na maior parte do tempo?

4 Você fez essa atividade durante o Recreio, Edu cação Física ou em outro momento após o sinal tocar para a aula começar? [Na coluna $\mathrm{F}$, codifique EF e o número de minutos das atividades físicas realizadas durante a Educação Física; R e o número de minutos das atividades realizadas durante o recreio; NA e o número de minutos das atividades realizadas em qualquer outro momento durante o período escolar]

5 Além do que já foi dito, você fez algum outro curso, aulas extras ou treinos ontem durante a escola? 


\section{Depois da Escola}

Esse é o período de tempo desde o sinal da escola tocar para a aula acabar até você ir dormir e inclui atividades realizadas na escola após o sinal tocar para a aula acabar. [Use a lista de atividades e pergunte sobre as realizadas ontem DEPOIS DA ESCOLA].

1 Você ontem, por 5 minutos ou mais, depois da escola?

[Para as atividades Exercícios, Caminhada, Corrida e Combinação de caminhada e corrida, perguntar se a criança já incluiu em outra atividade o tempo que ela gastou nessas atividades.]

2 Quantos minutos você realmente gastou ?

3 Durante os_ minutos em que você esteve , você sentiu "dificuldade para respirar" ou "sensação de cansaço" nunca, às vezes ou na maior parte do tempo?

4 Além do que já foi dito, você fez algum outro curso, aulas extras ou treinos ontem depois da escola?

\section{Atividades Sedentárias}

[Para ser pesquisado depois que a atividade física já tiver sido investigada]

Agora vou lhe perguntar sobre televisão/vídeo e computador ou videogames ANTES DA ESCOLA.

Você assistiu televisão/vídeo por 5 minutos ou mais antes da escola ontem? Quanto tempo você ficou assistindo televisão/vídeo? Quais programas você assistiu? Você usou computador ou videogame por mais de 5 minutos ontem antes da escola? Quanto tempo ficou no computador ou videogame?

Agora vou lhe perguntar sobre televisão/vídeo e computador ou videogames DEPOIS DA ESCOLA.

Você assistiu à televisão/vídeo por 5 minutos ou mais depois da escola ontem? Quanto tempo você ficou assistindo à televisão/vídeo? A quais programas você assistiu? Você usou computador ou videogame por mais de 5 minutos ontem depois da escola? Quanto tempo ficou ao computador ou videogame?

\section{Seção A: DADOS INICIAIS DA ENTREVISTA}

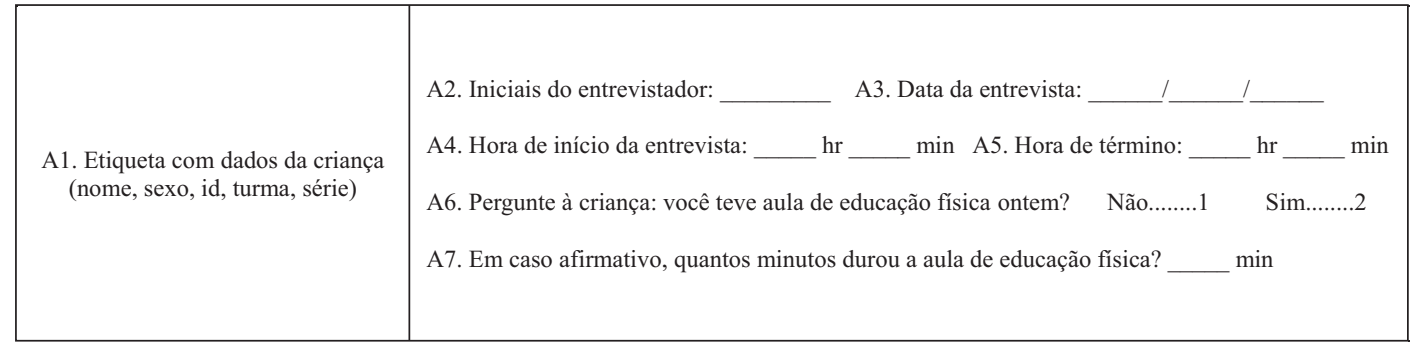




\section{GUIA DE PERGUNTAS}

1. Assuma que a maioria das brincadeiras/jogos não é contínua. Não é necessário investigar o tempo parado em jogos como pique-bandeira, queimada ou jogos de revezamento.

2. Pergunte sobre tempo de descanso (de pausa). Subtraia do total e dê uma informação de retorno.

3. Se forem mencionados treinos, subdivida-os e pergunte as características particulares. Faça anotações específicas separadamente.

4. Se um esporte praticado não for parte de um treino oficial de uma equipe, pergunte quanto tempo a criança esteve "no jogo" ou "realmente jogou".

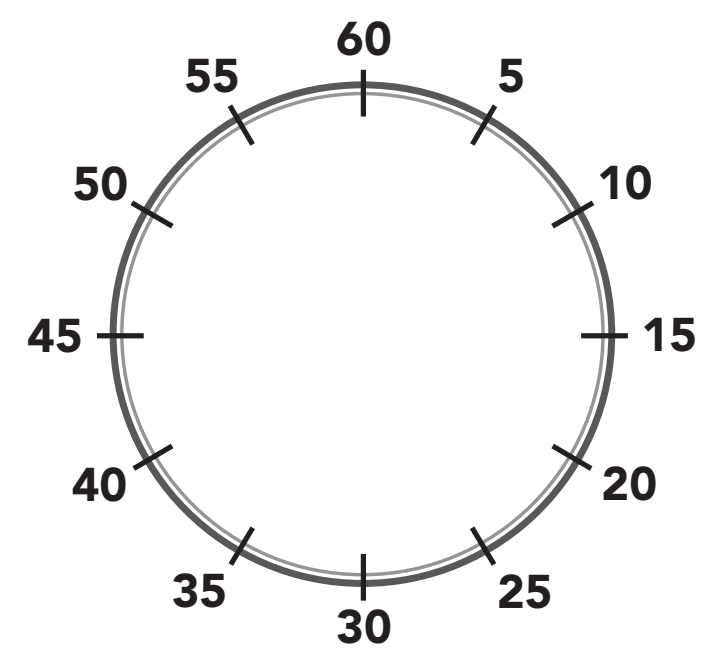

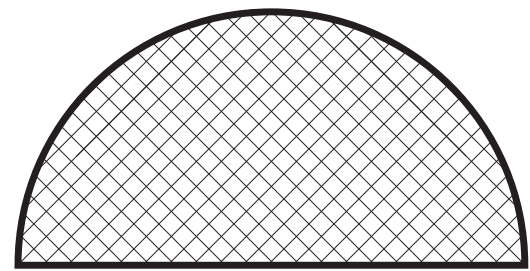

30 MINUTOS

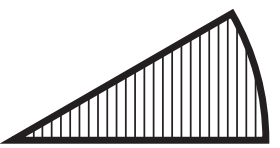

5 MINUTOS

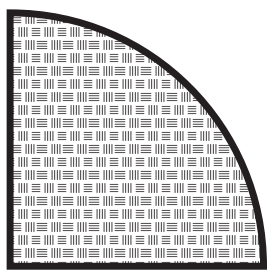

15 MINUTOS 


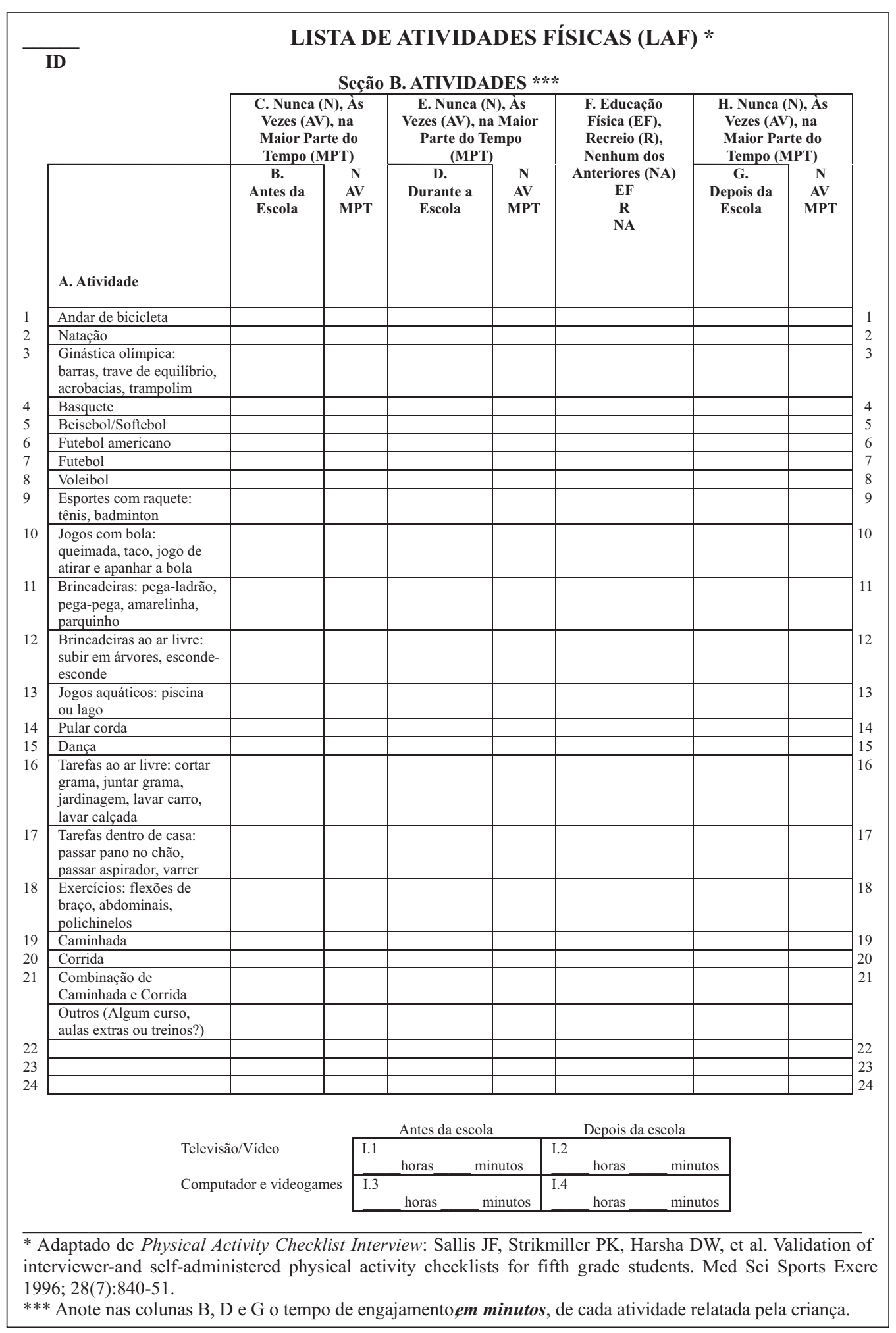




\section{Seção C. AVALIAÇÃo DA ENTREVISTA}

C1. AVALIAÇÃO GERAL DA ENTREVISTA COM O PARTICIPANTE:

\begin{tabular}{|c|c|}
\hline Ruim & . \\
\hline Regular & ........ \\
\hline Boa & 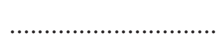 \\
\hline Muito boa & . \\
\hline Excelente & $\ldots$ \\
\hline
\end{tabular}

C2. ATENÇÃO DO PARTICIPANTE:

$\begin{array}{rrr}\text { Ruim } & \ldots \ldots \ldots \ldots \ldots \ldots \ldots \ldots . & 1 \\ \text { Regular } & \ldots \ldots \ldots \ldots \ldots \ldots \ldots \ldots \ldots & 2 \\ \text { Boa } & \ldots \ldots \ldots \ldots \ldots \ldots \ldots \ldots & 3 \\ \text { Muito boa } & \ldots \ldots \ldots \ldots \ldots \ldots \ldots \ldots \ldots & 4 \\ \text { Excelente } & \ldots \ldots \ldots \ldots \ldots \ldots \ldots \ldots . & 5\end{array}$

C3. HABILIDADE DO PARTICIPANTE PARA LEMBRAR-SE DAS ATIVIDADES:

\begin{tabular}{|c|c|}
\hline Ruim & . \\
\hline Regular & $\ldots$. \\
\hline Boa & ....... \\
\hline Muito boa & 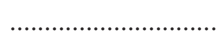 \\
\hline Excelente & .............. \\
\hline
\end{tabular}

C4. HABILIDADE DO PARTICIPANTE PARA ESTIMAR O TEMPO:

\begin{tabular}{|c|c|}
\hline Ruim & 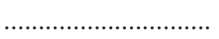 \\
\hline Regular & ........ \\
\hline Boa & ............. \\
\hline Muito boa & ...... \\
\hline Excelente & 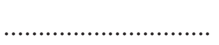 \\
\hline
\end{tabular}

C5. NÍVEL DE COOPERAÇÃO:

\begin{tabular}{|c|c|}
\hline Ruim & 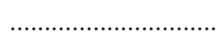 \\
\hline Regular & ......... \\
\hline Boa & ...... \\
\hline Muito boa & 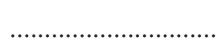 \\
\hline Excelente & 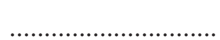 \\
\hline
\end{tabular}

C6. CREDIBILIDADE DA ENTREVISTA:

\begin{tabular}{|c|c|}
\hline Ruim & ㄱ...………… \\
\hline Regular & . \\
\hline Boa & ...... \\
\hline Muito boa & $\ldots \ldots \ldots$ \\
\hline Excelente & . \\
\hline
\end{tabular}


Termos gerais e relativos ao tipo de atividade física que foram suprimidos, substituídos ou acrescentados

\begin{tabular}{|c|c|}
\hline Termos & Alterações \\
\hline \multicolumn{2}{|l|}{ Gerais } \\
\hline Suprimidos & $\begin{array}{l}\text { - Nome do estudo original; a menção da versão do formulário, por não haver mais de uma; e a indicação do idioma no qual foi } \\
\text { realizada a entrevista }\end{array}$ \\
\hline \multirow[t]{2}{*}{ Substituídos } & $\begin{array}{l}\text { - A palavra "desloca" foi utilizada no lugar da palavra "move", uma vez que era necessária a idéia de mudança de um lugar para } \\
\text { o outro }\end{array}$ \\
\hline & $\begin{array}{l}\text { - A sentença "you can do in one place" referindo-se à execução de uma atividade física específica foi substituída em português } \\
\text { por "podem ser feitas sem sair do lugar" e não "você pode fazer em um só lugar" conforme sugestão dos tradutores } \\
\text { - Na frase "Caminhar do carro para a escola? (mais ou menos de } 5 \text { minutos?)" a preposição "para" foi substituída por "até"; "at } \\
\text { one time" referindo-se à execução da atividade física sem interrupção foi substituído por "seguidos" }\end{array}$ \\
\hline Acrescentados & $\begin{array}{l}\text { - A palavra "somente" na frase "Nós estamos interessados somente no tempo em que você realmente fez atividade física" para } \\
\text { enfocar que o tempo sem atividade física não pode ser considerado } \\
\text { - Na frase "Pense sobre ontem antes da escola" foi acrescida a palavra "período" para reforçar a idéia do dia dividido em três } \\
\text { partes } \\
\text { - A palavra "Escola" foi acrescentada na frase "Este período vai desde que você acordou até o sinal da Escola tocar para a aula } \\
\text { começar (inclui atividades realizadas antes de a aula começar)" para elucidar que as atividades realizadas antes de a aula começar } \\
\text { deveriam ser incluídas no período antes da Escola }\end{array}$ \\
\hline \multicolumn{2}{|l|}{$\begin{array}{l}\text { Relativos ao tipo de } \\
\text { atividade física }\end{array}$} \\
\hline Suprimidos & $\begin{array}{l}\text { - A atividade física "four square", que é um jogo que utiliza bola e um espaço dividido em quatro quadrantes numerados, tendo } \\
\text { como objetivo alcançar a melhor classificação, para isso arremessa-se a bola em direção ao quadrado de maior valor. Não foi } \\
\text { encontrada atividade equivalente }\end{array}$ \\
\hline Substituídos & $\begin{array}{l}\text { - O termo "kickball" foi substituído por "taco", por apresentarem características semelhantes quanto aos tipos de movimentos, } \\
\text { utilização de bola e bastão, distribuição espacial dos participantes } \\
\text { - A atividade "chase" por "pega-ladrão", uma vez que "chase" se refere a um jogo onde ocorre "perseguição" e "caça", } \\
\text { apresentando características de atividades intermitentes }\end{array}$ \\
\hline
\end{tabular}

foram classificados como tendo significados inalterados, $15 \%$ pouco alterado, $7,5 \%$ muito alterado e 7,5\% completamente alterado.

Em relação ao significado referencial, houve ajustes necessários na sintaxe de algumas frases com base na avaliação da retradução: nome do questionário original retraduzido (Lista de Atividade Física [LAF] - Physical Activity List for the Inteview); e frases relativas à noção do tempo, alteradas para: "O que dura 60 minutos?”; "Qual pedaço representa 15 minutos?”; “[A criança segura o relógio e coloca as peças nos lugares corretos]” (Figura 2).

No item do PACI relativo às informações sobre a divisão do dia em três partes, observou-se existência de diferença de significado entre a versão original e a retraduzida para a frase "For each segment we will ask which physical activity you did for 5 minutes or more using a checklist". Após discussão, optou-se por mantê-la como proposto na versão preliminar. No item sobre a entrevista, 11 frases apresentaram diferença de significado referencial, entretanto todas permaneceram conforme a versão preliminar. Por exemplo: (1) original - "This is the time from when you woke up until the bell rang for school to start (includes early care on school premises)"; versão preliminar: esse é o período a partir do momento em que o sinal da escola toca até você ir dormir (inclui atividades após a escola); (2) original: "What did you do before school in general?"; versão preliminar: O que você fez, de modo geral, antes de ir para a escola? Todas as alterações realizadas podem ser encontradas em Cruciani 11.

Entre as atividades físicas, detectou-se falta de semelhança de significado referencial para quatro tipos de atividade física: "Tumbling, Kickball, Chase, Mixed walking/running”. Tais atividades permaneceram como na versão preliminar: acrobacias, taco, pega-ladrão, combinação de caminhada e corrida.

Sob o ponto de vista dos significados conotativos, identificaram-se modificações para algumas questões. No item referente à noção de tempo (habilidade para quantificar o tempo em minutos), foi identificada falta de semelhança de 
significado em cinco frases: "We're going to ask you how long you did physical activity yesterday"; "What is something that last this whole $60 \mathrm{~min}$ utes?”; "This last piece is how long?”; "[Child holds clock, put away pieces]"; "You may do a physical activity for 5, 10, 20 or more than 60 minutes". Somente duas frases foram modificadas na versão preliminar em português para: "O que dura 60 minutos?”; “[A criança segura o relógio, e coloca as peças nos lugares corretos]". O restante permaneceu como na versão preliminar 11 .

No item que apresenta as questões relativas às atividades físicas realizadas, nove frases foram identificadas como apresentando significados conotativos diferentes ${ }^{11}$. Somente a frase "Esse é o período a partir do momento em que o sinal da Escola toca até você ir dormir (inclui atividades realizadas na Escola após o sinal tocar)" foi modificada para "Esse é o período de tempo desde o sinal da escola tocar para a aula acabar até você ir dormir e inclui atividades realizadas na escola após o sinal tocar para a aula acabar".

Referente aos tipos de atividades físicas, observou-se falta de significado conotativo em algumas frases, optando-se por mantê-las como proposto na versão preliminar. Na parte "Probing Guidelines” do PACI, verificou-se diferença de significado referencial para a frase "Assume most play/games are not continuous (do not have to probe for resting/waiting time in games like 4 square, relays)", entretanto foi mantida a frase em português "Assuma que a maioria das brincadeiras/jogos não são contínuas. Não é necessário investigar o tempo parado em jogos como piquebandeira, queimada ou jogos de revezamento".

No pré-teste foram identificados: (i) Problemas no preenchimento da Seção C do LAF. Tal seção apresenta categorias subjetivas e propõe uma avaliação dos aspectos relativos ao escolar: atenção, habilidade para lembrar as atividades, habilidade para estimar o tempo, nível de cooperação e, ainda, credibilidade e avaliação geral da entrevista, com categorias ruim, regular, boa, muito boa e excelente. Assim, um escolar de 7 anos poderia ser classificado como apresentando nível de cooperação ruim, quando de fato apresentava pouca habilidade para lembrar as atividades. Além disso, poderia haver erros de classificação dos itens, particularmente para as alternativas regular/boa e muito boa/excelente. Tais erros podem ser maximizados se for considerado o formato do instrumento que contém perguntas muito padronizadas e repetitivas ("Você, andou de bicicleta, ontem, antes da escola por 5 minutos ou mais?") com substituição somente do tipo de atividade (no total 21), gerando cansaço tanto no entrevistador como na criança. Ressalta-se que essas perguntas são elaboradas para os três períodos do dia: antes, durante e após a escola. Sugere-se, portanto, que a Seção C seja utilizada como material para entender possíveis valores outliers e que não haja a repetição de toda a frase ("Você, andou de bicicleta, ontem, antes da escola por 5 minutos ou mais?”) para cada tipo de atividade física do LAF, em cada período; (ii) algumas crianças, especialmente as de 7 anos, apresentaram maior dificuldade em estimar o tempo em minutos de atividade física ou ocupação sedentária, necessitando utilizar as peças do relógio para ajudá-las na estimativa do tempo; (iii) nas questões relativas à ocupação sedentária, encontrou-se também dificuldade na quantificação. A estratégia de questionar sobre os programas de TV vistos foi útil para a verificação desse comportamento; (iv) no que se refere ao tipo de atividade física, constatou-se que as mais citadas são o futebol, a caminhada, a corrida, as brincadeiras (pega-pega, pega-ladrão, amarelinha), os jogos com bola (queimada, taco e jogar e apanhar a bola) e os exercícios (flexão de braço, abdominais e polichinelos); (v) algumas atividades físicas, entretanto, não foram citadas: beisebol/softebol, futebol americano e esportes com raquete (badminton, tênis), e outras foram relatadas sem constarem na lista: kung-fu e patinar. Optou-se por manter o instrumento adaptado sem alteração, mantendo as atividades não citadas e não incluindo as mencionadas; (vi) grande parte dos entrevistados não entendia o que significa a palavra "trote" que faz parte da Seção B: "Atividades", sempre havendo necessidade de explicação; por isso, optou-se por trocar a atividade "intercalou caminhada e trote" por "intercalou caminha e corrida"; (vii) o tempo mediano de aplicação da versão adaptada - LAF - foi de 30 minutos (valor mínimo = 19 minutos; valor máximo = 52 minutos); o do questionário original - PACI -, de 17,5 minutos.

\section{Discussão}

Seguindo modelo de adaptação transcultural 6,9,10, o presente estudo realiza a apreciação das equivalências conceitual, de itens e semântica de um instrumento já validado para crianças americanas que permite a aferição da atividade física em crianças de 7 a 10 anos. Pelas características de baixo custo e facilidade de aplicação de questionários para a aferição de atividade física e, ainda, pela lacuna de instrumentos brasileiros voltados para a faixa etária de 7 a 10 anos, identificou-se como importante a realização deste estudo.

A leitura e a reflexão sobre os conceitos de movimento físico e sua conversão em gasto energético na faixa etária de 7 a 10 anos possibilitaram 
a realização da equivalência conceitual e de itens com base no espaço de mensuração do construto atividade física. Os itens do instrumento original referentes a atividades sedentárias, apesar de não fazerem parte do espaço conceitual de interesse do estudo, foram consideradas como não interferindo na aferição de atividade física e, de certo modo, complementares a ela.

\section{Equivalências conceitual e de itens}

Segundo Ciconelli 16 e Oku et al. 17, ao se propor a adaptação de um questionário, há a necessidade de se considerar as diferentes características existentes em cada sociedade, como crenças, costumes e comportamentos. O questionário deve ser composto por linguagem simples e clara, atingindo a equivalência quanto aos conceitos culturais.

No presente estudo, foram consideradas as dimensões da atividade física: lazer, domésticas, de transporte e ocupacionais 18 , de modo semelhante à Cale 19, que utilizou atividade física na escola (excluindo esporte), esporte na escola, atividade física durante o tempo de lazer e esporte durante tempo de lazer.

O LAF, por meio da lista de atividades, cobre todas as dimensões. Entre as atividades de lazer, quatro tipos de atividades físicas são praticadas essencialmente no país de origem: "four square", "beisebol", "softebol" e "futebol americano". Essas atividades, quando praticadas, correspondem a um "espaço" de mensuração do construto específico, sendo complicada a retirada ou substituição por outro tipo. Como não é praticado na cultura alvo, este "espaço" poderia ser preenchido por atividades físicas cuja prática resulte em gasto energético semelhante. Para tanto, seria de utilidade realizar um levantamento de atividades de lazer e buscar associação entre elas nas duas culturas, para decidir sobre as práticas apresentadas no questionário que não são comuns no Brasil.

Mesmo na ausência de um levantamento de atividade física, o questionário parece cobrir grande parte das atividades físicas realizadas no Brasil por este grupo populacional. Sente-se falta, entretanto, das atividades: capoeira, futsal, artes marciais (caratê, judô), pingue-pongue que são comuns na faixa etária estudada. Tal constatação não foi feita com base nos dados coletados no pré-teste. A amostra estudada foi reduzida e não permitiu a identificação de atividades físicas não incluídas no questionário.

\section{Equivalência semântica}

Reichenheim \& Moraes 6 reforçam a importância de serem realizadas duas ou mais traduções do documento original para se obter diferentes opções de termos a serem utilizados na versão traduzida. Seguindo essa recomendação, foram realizadas três traduções, proporcionando mais opções e facilitando as tomadas de decisão na construção do documento adaptado, com conseqüente melhor estrutura lingüística em português.

Moraes et al. 12 identificaram como facilitador na formulação da versão síntese a inclusão de mais de um par de tradução-retradução. Ressaltam, contudo, que não há uma recomendação quanto ao número ideal de pares, pois isso difere de acordo com a situação de cada pesquisa. Neste estudo foi realizada uma única retradução.

A avaliação da retradução foi útil na revisão dos termos utilizados e identificados na avaliação de significados conotativo ou referencial. Foi o caso, por exemplo, da pergunta "What is something that last this whole 60 minutes?", na versão preliminar era "Que coisas duram 60 minutos?", retradução era "What things last for 60 minutes?" e na versão final ficou "O que dura 60 minutos?". Pode-se identificar melhora na versão final do instrumento se comparado à versão preliminar.

O processo de equivalência semântica resultou em um questionário sem ambigüidades, com expressões comuns e adaptado à cultura brasileira, uma vez que quase o total de atividades físicas mencionadas na cultura de origem encontraram equivalentes na cultura alvo.

Em relação às crianças mais novas, especialmente as de 7 anos, destacou-se a necessidade de cuidados adicionais, especialmente na explicação sobre estimativa de tempo, conceitos de atividade física e do próprio instrumento. Os autores acreditam que tais cuidados podem minimizar os efeitos da menor capacidade cognitiva de crianças nessa idade.

Ressalta-se que tanto o questionário original quanto o adaptado não podem ser aplicados se o dia anterior não for um dia escolar. No caso de as crianças avaliadas estudarem no período da manhã, deve-se atentar ao período após a escola, pois ele será maior do que no formato original, sugerindo assim, que considere o tempo total da atividade após a escola.

Para o LAF, deve-se usar o compêndio de atividade física de Ainsworth et al. 8 a fim de calcular os escores de atividades físicas (ponderado e não ponderado), já que ele foi utilizado no instrumento original. Frisa-se, no entanto, que a estimativa do custo metabólico de atividades (MET) pode variar segundo o compêndio utilizado. O 
compêndio de Ainsworth et al. 8 foi desenvolvido para a população adulta e o efeito do uso de tais referências em populações de crianças é pouco explorado na literatura, podendo constituir procedimento não adequado 20 . Ridley et al. 21 publicaram um compêndio de atividades físicas específico para crianças e adolescentes; há, entretanto, necessidade de estudos que utilizem o compêndio proposto e que forneçam elementos para sua indicação.

A adaptação transcultural da LAF para uso em escolares de 7 a 10 anos foi concluída até a equivalência semântica, faltando a apreciação das equivalências de mensuração para que o LAF seja considerado adaptado à cultura brasileira.

\section{Considerações finais}

Por meio deste estudo, que teve como principal objetivo realizar as etapas iniciais da adaptação transcultural no que diz respeito à apreciação das equivalências conceitual, de itens e semântica de questionário já validado em crianças americanas, considera-se que: (i) o LAF apresenta equivalência conceitual porque abarca o construto de interesse em suas diferentes dimensões; (ii) foi necessário ajustar alguns tipos de atividade física para que fosse conferida equivalência de itens ao LAF; (iii) o LAF apresenta equivalência semântica conforme processo de avaliação de significado conotativo e referencial; (iv) o LAF requer, ainda, o cumprimento das etapas de avaliação de equivalência de mensuração e operacional, para que se complete sua adaptação transcultural.

\section{Resumo}

Há lacuna de questionários de atividade física para crianças brasileiras. O Physical Activity Checklist Interview (PACI), desenvolvido em crianças americanas, permite aferir atividade física do dia anterior. Constituem objetivos do estudo: (i) descrever os procedimentos envolvidos na escolha do PACI a ser submetido à adaptação transcultural; (ii) avaliar equivalências conceitual, de itens e semântica da versão adaptada para uso em crianças de 7 a 10 anos. Identificou-se o PACI pela revisão sistemática na qual foram incluídos dezoito questionários. Foram realizadas, no processo de escolha do instrumento, discussões com pesquisadores da área de atividade física. Verificou-se que o PACI permite aferir o construto e dimensões nas populações de origem e alvo, sendo necessário suprimir algumas atividades por não serem comuns na população alvo. Na equivalência semântica, realizou-se tradução, retradução e avaliação dos significados conotativo e referencial, com pré-teste em 24 crianças de 7 a 10 anos. Apresenta-se a versão do PACI adaptada, denominada Lista de Atividades Físicas ( $L A F)$.

Atividade Física; Questionários; Crianças

\section{Colaboradores}

F. Cruciani participou da concepção do trabalho, das análises e interpretação e da escrita do artigo. F. Adami participou da revisão crítica e da escrita do artigo. N. A. Assunção participou das análises e interpretação dos dados. D. P. Bergamaschi participou da concepção do projeto, da análise e interpretação dos dados e da redação do artigo.

\section{Agradecimentos}

Ao Programa de Incentivo à Pesquisa da Universidade de São Paulo (ProIP); aos participantes, pais e responsáveis; e aos professores, coordenação e direção da Escola de Aplicação da USP. 


\section{Referências}

1. Caspersen C, Powell K, Christensen G. Physical activity, exercise and physical fitness: definitions and distinction for health-related research. Public Health Rep 1985; 100:126-31.

2. Katzmarzyk PT, Baur LA, Blair SN, Lambert EV, Oppert JM, Riddoch C. International conference on physical activity and obesity in children: summary statement and recommendations. Int J Pediatr Obes 2008; 3:3-21.

3. Kohl HW, Fulton JE, Caspersen CJ. Assessment of physical activity among children and adolescents: a review and synthesis. Prev Med 2000; 31:S54-76.

4. Barros MVG, Assis MAA, Pires MC, Grossemann S, Vasconcelos FAG, Luna MEP, et al. Validity of physical activity and food consumption questionnaire for children aged seven to ten years old. Rev Bras Saúde Matern Infant 2007; 7:437-48.

5. Koga CR. Estudo nutricional de escolares de 7 a 10 anos de idade: diagnóstico e comparação de métodos [Dissertação de Mestrado]. São Paulo: Faculdade de Saúde Pública, Universidade de São Paulo; 2005.

6. Reichenheim ME, Moraes CL. Operacionalização de adaptação transcultural de instrumentos de aferição usados em epidemiologia. Rev Saúde Pública 2007; 41:665-73.

7. Sallis JF, Strikmiller PK, Harsha DW, Feldman HA, Ehlinger S, Stone EJ, et al. Validation of interviewer- and self-administered physical activity checklists for fifth grade students. Med Sci Sports Exerc 1996; 28:840-51.

8. Ainsworth BE, Haskell WL, Leon AS, Jacobs Jr. DR, Montoye HJ, Sallis JF, et al. Compendium of physical activities: classification of energy costs of human physical activities. Med Sci Sports Exerc 1993; 25:71-80.

9. Herdman M, Fox-Rushby J, Badia X. "Equivalence" and the translation and adaptation of health-related quality of life questionnaires. Qual Life Res 1997; 6:237-47.

10. Herdman M, Fox-Rushby J, Badia X. A model of equivalence in the cultural adaptation of HRQoL instruments: the universalist approach. Qual Life Res 1998; 7:323-35.

11. Cruciani F. Adaptação transcultural de instrumento para avaliação da atividade física de crianças de 7 a 10 anos de idade: avaliação das equivalências conceitual, de itens, semântica e operacional [Dissertação de Mestrado]. São Paulo: Faculdade de Saúde Pública, Universidade de São Paulo; 2008.
12. Moraes CL, Hasselmann MH, Reichenheim ME. Adaptação transcultural para o português do instrumento "Revised Conflict Tactics Scales (CTS2)" utilizado para identificar violência entre casais. Cad Saúde Pública 2002; 18:163-76.

13. Crocker P, Bailey D, Faulkner R, Kowalski K, McGrath R. Measuring general levels of physical activity: preliminary evidence for the physical activity questionnaire for older children. Med Sci Sports Exerc 1997; 29:1344-9.

14. Kowalski KC, Crocker PRE, Faulkner RA. Validation of the Physical Activity Questionnaire for Older Children. Pediatr Exerc Sci 1997; 9:174-86.

15. Scerpella TA, Tuladhar P, Kanaley JA. Validation of Godin-Shephard questionnaire in prepubertal girls. Med Sci Sports Exerc 2002; 34:845-50.

16. Ciconelli RM. Tradução para o português e validação do questionário genérico de avaliação de qualidade de vida "Medical Outcome Study 36 -Item Short - Form Health Survey (SF-36)" [Tese de Doutorado]. São Paulo: Universidade Federal de São Paulo; 1997.

17. Oku EC, Andrade AP, Stadiniky SP, Carrera EF, Tellini GG. Tradução e adaptação cultural do ModifiedUniversity of California at Los Angeles Shoulder Rating Scale para a língua portuguesa. Rev Bras Reumatol 2006; 46:246-52.

18. Mendonça CP, Anjos LA. Aspectos das práticas alimentares e da atividade física como determinantes do crescimento do sobrepeso/obesidade no Brasil. Cad Saúde Pública 2004; 20:698-709.

19. Cale L. Self-report measures of children's physical activity: recommendations for future development and a new alternative measure. Health Educ J 1994; 53:439-53.

20. Harrell JS, McMurray RG, Baggett CD, Pennell ML, Pearce PF, Bangdiwala SI. Energy costs of physical activities in children and adolescents. Med Sci Sports Exerc 2005; 37:329-36.

21. Ridley K, Ainsworth BE, Olds TS. Development of a compendium of energy expenditures for youth. Int J Behav Nutr Phys Act 2008; 5:45.

Recebido em 03/Fev/2010

Versão final reapresentada em 07/Out/2010 Aprovado em 13/Out/2010 